\title{
Input-Output Organization of the Sensorimotor Striatum in the Squirrel Monkey
}

\author{
Alice W. Flaherty ${ }^{1,2}$ and Ann M. Graybiel ${ }^{1}$ \\ 'Department of Brain and Cognitive Sciences, Massachusetts Institute of Technology, Cambridge, Massachusetts 02139 \\ and ${ }^{2}$ Division of Health Sciences and Technology, Harvard Medical School, Boston, Massachusetts 02115
}

The basal ganglia receive massive inputs from the neocortex and send outputs that exert both inhibitory and disinhibitory control over parts of the frontal cortex and brainstem. Between these basal ganglia inputs and outputs lies the striatum, which receives most of the cortical afferents and projects to the basal ganglia output nuclei-the globus pallidus and substantia nigra. To analyze this system we conjointly labeled, in squirrel monkeys, sensorimotor cortical inputs to the striatum and striatal outputs to the globus pallidus. Anterograde tracers were injected into the motor (MI) and somatosensory (SI) cortical body maps, at sites determined by electrophysiological stimulation and recording. Retrograde tracers were stereotaxically injected into the external and internal pallidal segments (GPe and GPi).

We found that multiple dispersed modules ("matrisomes") in the putamen that all received inputs from single body-part representations in sensorimotor cortex could, in turn, send convergent outputs to single sites in the pallidum. This divergence-reconvergence pattern was found for both GPe and GPi sites, and for inputs from both SI and MI cortex. Thus, information from a single functional region in the cortex can be split up at the striatal stage only to be brought back together in the pallidum. The temporary divergence may increase lateral interactions between sensorimotor matrisomes, as well as between matrisomes and striosomes. One function of striatal modularity may thus be to set up an associative network in the striatum, which might contribute to sensorimotor learning. We also found that some sets of matrisomes did not receive strong sensorimotor inputs, even though they projected to regions of GPe and GPi that are near the sensorimotor-recipient zones described above. Thus, the matrisomal system may sort Ml/SI inputs and other inputs before transfer to paired regions of GPe and GPi.

[Key words: basal ganglia, primate, putamen, motor cortex, somatosensory cortex, globus pallidus, motor systems, enkephalin, tract tracing, sensory-motor associations, motor learning, Parkinson's disease, Huntington's disease]

\footnotetext{
Received Feb. 8, 1993; revised May 26, 1993; accepted July 15, 1993.

We thank H. F. Hall for his help with the photography, and C. Shneider and G. Holm for their help with manuscript processing. This work was funded by Javits Award NIH ROINS25529, the Human Frontier Science Program, and by NIH EY02866.

Correspondence should be addressed to Ann M. Graybiel, E25-618 MIT, Cambridge, MA 021139

Copyright (C) 1994 Society for Neuroscience $0270-6474 / 94 / 140599-12 \$ 05.00 / 0$
}

The basal ganglia have been implicated in neurological and neuropsychiatric disorders ranging from Huntington's disease and Parkinson's disease to obsessive-compulsive disorder ( $\mathrm{Al}-$ bin et al., 1989; Baxter et al., 1992; Rubin et al., 1992; Swedo et al., 1992). The nature of processing in the basal ganglia is still obscure, but the basal ganglia are known to have two unusual features. First, their net output inhibits its targets. The inhibition depends on the relative activity in the internal or external segments of the globus pallidus (GPi or GPe) and, for brainstem targets, on similar circuits involving the substantia nigra pars reticulata ( $\mathrm{SNpr}$ ). The second striking feature of the system is that its main input nucleus, the striatum, has widespread inputs (including inputs from the entire neocortex), but has only a small set of outputs (for review, see Crossman, 1987; Albin et al., 1989; Alexander and Crutcher, 1990; Parent and Hazrati, 1993).

Current models of basal ganglia processing emphasize the first feature, but do little to account for the massive convergence from the neocortex to the striatum and from the striatum to the next steps in the circuit, the GP and the SNpr. Approaching this question experimentally has been difficult because of the technical limitations in studying more than one synaptic link in the system at the same time (Hoover and Strick, 1993). In the experiments we report here, we examined input-output processing in the corticostriatopallidal pathway by combining electrophysiological rccording, stimulation, and antcrograde and retrograde tracer injections in single squirrel monkey brains. We focused on the inputs from primary motor cortex (MI) and somatosensory cortex (SI), because these regions of the neocortex are relatively well characterized and are important in movement control.

Our strategy depended on the fact that the corticostriatal input fibers and striatopallidal output neurons are organized in a patchy way within the striatum, rather than being smoothly distributed. Because these "patches" are distinct from striosomes, and are found in the matrix of the striatum, we have called them matrisomes (Graybiel et al., 1991). In the monkey, anterograde tracer experiments show that single small sites in the body maps of motor cortex and somatosensory cortex send inputs to multiple matrisomes in the putamen's sensorimotor sector (Flaherty and Graybiel, 1991, 1993a). The matrisomes labeled from homologous body part representations in MI and SI areas (4, 3a, $3 b, 1)$ overlap each other. Similarly, injections of retrograde tracer placed in single sites in either GPe or GPi label discrete clusters of striatal neurons (output matrisomes) in the putamen's sensorimotor sector (Giménez-Amaya and Graybiel, 1991). What has been unclear is whether the input matrisomes and output matrisomes are systematically related to each other. 
To resolve this question, we labeled both corticostriatal inputs and striatopallidal outputs in single hemispheres. Our results suggest the existence of a remarkable two-step design in which information from a single body part representation in the neocortex can first diverge to multiple loci in the striatum, which then can send convergent inputs to a single small site in the pallidum. Such divergent-convergent organization, if widespread, could underlie a role of the striatum in forms of associative processing, possibly including forms that could function in sensorimotor learning.

\section{Materials and Methods}

One or more pairs of anterograde and retrograde tracer injections were made in 25 hemispheres in 14 squirrel monkeys (Saimiri sciureus). Many of these monkeys were also used in previous studies. Surgical protocols, electrophysiological recording and stimulating techniques, and tracer injections have been described in the corresponding reports (Flaherty and Graybicl, 1993a,b). Monkcys werc given a small dosc of the analgesic buprenorphine $\mathrm{HCl}(0.01 \mathrm{mg} / \mathrm{kg}, \mathrm{s.c}$.) preoperatively, and then were anesthetized with ketamine $(30 \mathrm{mg} / \mathrm{kg}, \mathrm{i} . \mathrm{m}$.) and a single initial dose of sodium pentobarbital $(5 \mathrm{mg} / \mathrm{kg}$, i.p.). A few monkeys did not receive buprenorphine, but instead received a larger dose of sodium pentobarbital $(10 \mathrm{mg} / \mathrm{kg}$, i.p.). Anesthetic level was determined by monitoring the electrocardiogram, respiration rate, muscle tone, and corneal and toe-pinch reflexes. Supplementary doses of ketamine $(10 \mathrm{mg} / \mathrm{kg}$, i.m.) were given as needed to maintain anesthesia.

Large bone and dural flaps were turned with sterile technique, the cortical surface was covered with high-viscosity silicone oil, and microelectrode penetrations were made at $500-1000 \mu \mathrm{m}$ intervals to determine the boundaries of body part representations in cortical areas 4 , $3 \mathrm{a}, 3 \mathrm{~b}$, and 1 . Electrode penetrations were made at depths that maximized the stimulated or recorded response, typically $800-1000 \mu \mathrm{m}$. The location of each cortical electrode penetration was marked on an enlarged photograph of the exposed cortex, and the stereotactic coordinate of each penetration was noted.

Multiunit neuronal activity was recorded with parylene-coated tungsten electrodes (Microprobe) with impedances of $0.8 \mathrm{M} \Omega \pm 15 \%$ at 1 $\mathrm{kHz}$. The borders of areas $3 \mathrm{a}, 3 \mathrm{~b}$, and 1 were determined as described previously (Flaherty and Graybiel, 1991). Receptive fields were identified by stimulating the skin with fine hand-held probes. Cutaneous fields were defined as regions from which a vigorous neural response could be elicited with very gentle tactile stimulation of the skin. Noncutaneous fields were defined as those unresponsive to light touch but sensitive to forceful taps or to manipulation of underlying tissues or joints.

MI was defined according to the criteria of Sessle and Wiesendanger (1982). Both intracortical electrical stimulation and cytoarchitectonic boundaries were examined. Trains of symmetric biphasic paired pulses, $0.3 \mathrm{msec}$ each, were delivered at $300 \mathrm{pulse}$-pairs/sec. Stimuli were delivered from an optically coupled stimulus isolator (Bak BSI-2) driven by a biphasic pulse generator (Bak RP-1), through platinum-iridium microelectrodes (Microprobe) with impedances of $1.0 \mathrm{M} \Omega \pm 5 \%$ at 1 $\mathrm{kHz}$. Current amplitude and pulse waveform were monitored intermittently on an oscilloscope by recording differentially across a $1 \mathrm{k} \Omega$ resistor in series with the microelectrode. Motor responses to microstimulation were considered to be present when either visible movement about a joint or visible muscle contraction occurred in a reproducible manner at a constant stimulus intensity. If movement was detected at $100 \mu \mathrm{A}$, the current was gradually lowered until the threshold value was reached. $\Lambda$ s little as $3 \mu \Lambda$ was sufficient to stimulate movement in monkeys that received small initial doses of sodium pentobarbital. In the few monkeys that received larger doses of sodium pentobarbital, thresholds of $20-40 \mu \mathrm{m}$ were more common. If no movement was detected, currents up to $400 \mu \mathrm{A}$ were tried briefly.

The anterograde neuronal tract tracers ${ }^{35} \mathrm{~S}$-methionine and wheat germ agglutinin-horseradish peroxidase conjugate (WGA-HRP) were then injected at electrophysiologically defined parts of the cortical body maps of area $4(\mathrm{MI})$ or areas $3 \mathrm{a}, 3 \mathrm{~b}$, and 1 of SI. The surgical levels of anesthesia suppressed pallidal responsiveness to sensorimotor stimulation, so we could not make electrophysiologically guided retrograde tracer injections in the pallidum as we did in the cortex. Therefore, we made stereotaxic injections in regions of GPe and GPi that pilot experiments showed to receive projections from the lateral putamen, the striatal region receiving most of the sensorimotor corticostriatal projection. The retrograde tracers injected were the $\beta$-subunit of cholera toxin (CTB) (Luppi et al., 1987) and enzymatically inactivated WGAHRP labeled with colloidal gold (HG) (Basbaum and Menetrey, 1987). All tracers were injected through glass pipettes with a pressure injection system (Picopump). After $2 \mathrm{~d}$ survival times, during which buprenorphine $(0.01 \mathrm{mg} / \mathrm{kg}$, s.c.) was given for analgesia twice daily, the monkeys were perfused under deep barbiturate anesthesia $(50 \mathrm{mg} / \mathrm{kg}$, i.p.). The brains were blocked, cryoprotected, and cut coronally at $40 \mu \mathrm{m}$ on a freezing microtome, as described previously (Flaherty and Graybiel, 1991).

As described previously, there was no significant difference in the extent of anterograde labeling by ${ }^{35} \mathrm{~S}-$ methionine or WGA-HRP (Flaherty and Graybiel, 1990), or of retrograde labeling by CTB or HG (Flaherty and Graybiel, 1993b). Typical injection site size did vary with the retrograde tracer, $\mathrm{HG}$ tending to produce smaller injection sites than CTB. There was no visible cross-reaction between any of the tracers used.

In most of the monkeys, we made injections in two different cortical sites and two different pallidal sites in each hemisphere. Such monkeys had up to eight separate pairs of anterograde and retrograde labeling to compare per brain. Most anterograde tracer deposits were relatively small (5-10 $\mu 1$ of tracer, resulting in 1-2 $\mathrm{mm}$ diameter sites) and approximately filled a single body part representation in a given cortical map, such as the foot representation in area $3 \mathrm{~b}$. Retrograde tracer injections of $60-90 \mu 1$ of $\mathrm{HG}$ and 15-20 $\mu \mathrm{l}$ of CTB produced similarly sized injection sites, about $0.5-1.5 \mathrm{~mm}$. In seven hemispheres we made much larger anterograde deposits. For instance, in monkey 35 we injected ncarly all of the motor cortex bilaterally, producing a $15 \times 4 \mathrm{~mm}$ ${ }^{35} \mathrm{~S}$-methionine injection site in the left hemisphere, and a $21 \times 4 \mathrm{~mm}$ WGA-HRP injection site on the right.

Adjacent sections were processed to compare the distributions of injected tracers, neurotransmitter-related compounds (enkephalin, tyrosine hydroxylase), and cell bodies (Nissl substance), according to standard histochemical protocols, described previously (Flaherty and Graybiel, 1993a,b). Anteroposterior levels of sections were assigned according to the atlas of Gergen and McLean (1962).

\section{Results}

All labeled striatal connections, whether traced anterogradely from the neocortex or retrogradely from the pallidum, were broken up into multiple rounded or bandlike zones of heavy labeling in the matrix compartment. The diameters of these zones, which were of varying sharpness, ranged from about 0.2 $\mathrm{mm}$ to $2 \mathrm{~mm}$. In between them were sparsely labeled and unlabeled regions. For both the retrograde and the anterograde tracer distributions, many, but not all, of the zones of label visible in single cross sections appeared to form parts of threedimensionally extended, branched projection systems. The larger tracer injections tended to also label a relatively uniform "main field" as well as the branching, more discontinuous zones. Such main fields were in regions of the putamen with no demonstrable striosomes, and accounted for up to approximately a third of the labeling in the cases in which they were seen. These results are in accord with previous observations (GiménezAmaya and Graybiel, 1990, 1991; Flaherty and Graybiel, 1991, 1993a,b). We did not repeat our earlier experiments showing that inputs from areas $3 \mathrm{a}, 3 \mathrm{~b}, 1$, and area 4 overlap with each other, but we did confirm that these ipsilateral inputs had only limited overlap with the corticostriatal inputs from contralateral MI (Flaherty and Graybiel, 1993a).

In all, there wcre 76 indepcndent pairs of anterogradely and retrogradely labeled projection fields that could be compared in the striatum, of which 31 pairs were placed so that they labeled the same part of the sensorimotor region of the putamen (Tables $1,2)$. Among these were cases providing dramatic evidence that the inputs and outputs could overlap systematically. In the remaining 45 pairs, the pallidal injections missed the desired target 


\section{A. Injection sites (40R)}

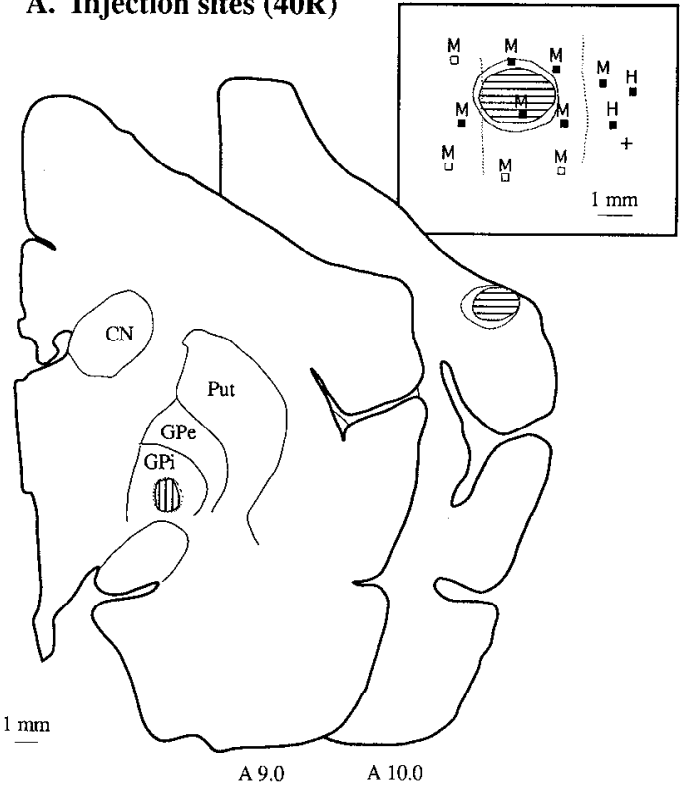

\section{B. Putamen: projections miss}

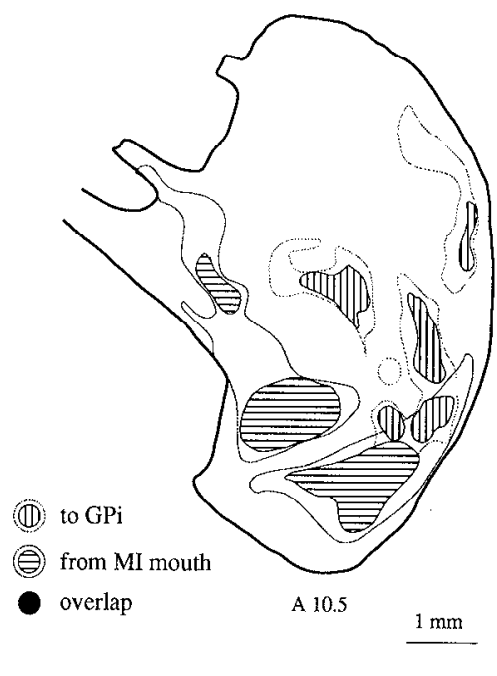

Figure 1. An injection site pair that labeled different regions of the striatum (a "miss" case). A, CTB injection site in GPi, and WGA-HRP injection site in the mouth region of MI (hemisphere 40R). The boxed inset shows an enlargement of the cortical injection site, viewed normal to the cortex and superposed on the electrophysiological map. Stimulating electrode penetration sites are marked by symbols: $\square$, movement stimulated less than $100 \mu \mathrm{A} ; \square$ movement stimulated $\geq 100 \mu \mathrm{A} ;+$, no stimulated response at $400 \mu \mathrm{A}$. $M$ mouth; $H$, hand. Straight dotted lines on the surface map are boundaries of Betz cell distribution. $C N$, caudate nucleus; Put, putamen. $B$, An overlay drawing of two serial coronal sections through the putamen, in which the MI mouth input matrisomes are all ventral to the GPi output matrisomes, and never overlap. The distribution of the GPi output matrisomes resembles that seen after injections in the trunk region of MI. Stereotaxic coordinates are listed beneath each coronal section. in the pallidum, either (1) retrogradely labeling districts of the striatum far from those receiving sensorimotor cortex projections, or (2) retrogradely labeling part of the sensorimotor putamen, but not the part of it that was anterogradely labeled. Figure 1 shows an example of such "miss" cases, in which an injection of anterograde tracer in the mouth region of motor cortex accordingly labeled the mouth-recipient zone of the putamen, but the tracer injection in GPi retrogradely labeled a region of putamen dorsal to the anterograde label, in a region that looked like the trunk-recipient zone of the putamen. There was no interdigitation or overlap of inputs and outputs in such topographically mismatched pairs. These "miss" cases are not described further in this report, but they were helpful in building up the picture of striatopallidal topography used to guide the retrograde tracer injections.

\section{The sensorimotor projection to the putamen innervates striatopallidal output zones}

There was significant overlap of labeled input and output zones in eight cases. In four of them (two with GPe injections and two with GPi injections), the overlap was especially extensive. Figures 2 and 3 illustrate two of these "overlap" cases, in which there was a nearly patch-for-patch lineup of MI corticostriatal input zones with output zones labeled from GPe (case 29R; Figs. $2 B, B ; 3 B, B$ ) and of SI corticostriatal input zones with output zones labeled from GPi (case $31 \mathrm{R}$; Figs. $2 A, A^{\prime} ; 3 A, A$ ). Not only the locations, but also the number, shape, and orientation of the input and output zones were similar. The main difference between the two types was their size: the larger an-

Table 1. Input-output injection site pairs: GPi

\begin{tabular}{|c|c|c|c|c|c|c|c|c|}
\hline \multirow[b]{2}{*}{ Result } & \multirow[b]{2}{*}{ Case } & \multirow[b]{2}{*}{ Tracer } & \multirow{2}{*}{$\begin{array}{l}\text { Ctx. } \\
\text { area }\end{array}$} & \multirow{2}{*}{$\begin{array}{l}\text { Body } \\
\text { part }\end{array}$} & \multirow{2}{*}{$\begin{array}{l}\text { GPi } \\
\text { tracer }\end{array}$} & \multicolumn{3}{|c|}{ GP coordinates } \\
\hline & & & & & & $\mathrm{A}$ & $\mathrm{H}$ & $\mathrm{L}$ \\
\hline Overlap & $31 \mathrm{R}$ & HRP & 4 & $\mathrm{ft}$ & СТВ & 9.0 & 11.5 & 6.5 \\
\hline Overlap & $39 \mathrm{R}$ & Met & 4 & $\mathrm{ft}$ & СТВ & 10.0 & 12.5 & 6.0 \\
\hline Overlap/interdig. & $40 \mathrm{~L}$ & Met & 4 & mth & СТВ & 9.0 & 11.5 & 6.0 \\
\hline Overlap/interdig. & $40 \mathrm{~L}$ & HRP & $\times 4$ & mth & CTB & 9.0 & 11.5 & 6.0 \\
\hline Interdig. & $35 \mathrm{~L}$ & HRP & 4 & all & $\mathrm{HG}$ & 9.0 & 12.5 & 6.5 \\
\hline Interdig. & $31 \mathrm{~L}$ & HRP & $3 a$ & hnd & CTB & 10.5 & 12.5 & 5.5 \\
\hline Interdig. & $34 \mathrm{~L}$ & Met & $\times 4$ & leg & $\mathbf{H G}$ & 9.5 & 13.0 & 7.0 \\
\hline Interdig. & $34 \mathrm{R}$ & HRP & $3 b$ & all & $\mathrm{HG}$ & 9.5 & 13.0 & 7.0 \\
\hline Interdig. & $34 \mathrm{~L}$ & HRP & $3 b$ & all & $\mathrm{HG}$ & 9.5 & 13.0 & 7.0 \\
\hline Interdig. & $34 \mathrm{R}$ & Met & 4 & leg & $\mathrm{HG}$ & 9.5 & 13.0 & 7.0 \\
\hline Interdig. & $39 \mathrm{R}$ & IIRP & 4 & hnd & CTB & 10.0 & 12.5 & 6.0 \\
\hline Interdig. & $39 \mathrm{~L}$ & HRP & 4 & $\mathrm{ft}$ & СТВ & 10.0 & 12.5 & 4.5 \\
\hline Interdig. & $31 \mathrm{~L}$ & Met & $3 a$ & $\mathrm{ft}$ & CTB & 10.5 & 12.5 & 5.5 \\
\hline Interdig. & $35 \mathrm{~L}$ & Met & $\times 4$ & all & $\mathrm{HG}$ & 9.0 & 12.5 & 6.5 \\
\hline
\end{tabular}

Cases are listed in order of decreasing overlap in the putamen between tracers transported from the cortex and GPi. $x$, projection from the contralateral hemisphere; $\mathrm{ft}$, foot region; mth, mouth region; hnd, hand region; trk, trunk region; A, anterior; $\mathrm{H}$, horizontal; $\mathrm{L}$, lateral. 


\begin{tabular}{|c|c|c|c|c|c|c|c|c|}
\hline \multirow{2}{*}{$\begin{array}{l}\text { Putamen } \\
\text { relation }\end{array}$} & \multirow[b]{2}{*}{ Case } & \multirow[b]{2}{*}{ Tracer } & \multirow{2}{*}{$\begin{array}{l}\text { Ctx. } \\
\text { area }\end{array}$} & \multirow{2}{*}{$\begin{array}{l}\text { Body } \\
\text { part }\end{array}$} & \multirow{2}{*}{$\begin{array}{l}\text { GPe } \\
\text { tracer }\end{array}$} & \multicolumn{3}{|c|}{ GP coordinates } \\
\hline & & & & & & $\mathrm{A}$ & $\mathrm{H}$ & $\mathrm{L}$ \\
\hline Overlap & $29 \mathrm{R}$ & IIRP & $3 b$ & $\mathrm{ft}$ & CTB & 10.5 & 13.0 & 7.0 \\
\hline Overlap & $39 \mathrm{R}$ & Met & 4 & $\mathrm{ft}$ & $\mathrm{HG}$ & 11.5 & 13.0 & 6.5 \\
\hline Overlap/interdig. & $39 R$ & HRP & $\times 4$ & $\mathrm{ft}$ & $\mathrm{HG}$ & 11.5 & 13.0 & 6.5 \\
\hline Overlap/interdig. & $35 \mathrm{~L}$ & HRP & 4 & all & СТВ & 10.5 & 13.0 & 7.0 \\
\hline Interdig. & $35 R$ & HRP & $\times 4$ & all & СТВ & 10.5 & 13.0 & 6.5 \\
\hline Interdig. & $29 L$ & Met & $3 b$ & all & CTB & 11.0 & 13.5 & 7.0 \\
\hline Interdig. & $34 \mathrm{R}$ & HRP & $3 b$ & all & CTB & 10.5 & 14.0 & 6.5 \\
\hline Interdig. & $35 \mathrm{~L}$ & Met & $\times 4$ & all & СТВ & 10.5 & 13.0 & 7.0 \\
\hline Interdig. & $29 \mathrm{~L}$ & HRP & 4 & all & СТВ & 11.0 & 13.5 & 7.0 \\
\hline Interdig. & $34 \mathrm{~L}$ & Met & $\times 4$ & leg & СТВ & 11.0 & 14.0 & 7.0 \\
\hline Interdig. & $34 \mathrm{~L}$ & HRP & $3 b$ & all & СТВ & 11.0 & 14.0 & 7.0 \\
\hline Interdig. & $34 \mathrm{R}$ & Met & 4 & leg & CTB & 11.0 & 14.0 & 6.5 \\
\hline Interdig. & $40 \mathrm{~L}$ & HRP & $\times 4$ & mth & $\mathrm{HG}$ & 9.5 & 13.5 & 7.0 \\
\hline Interdig. & $39 \mathrm{~L}$ & Met & 4 & hnd & $\mathrm{HG}$ & 11.0 & 13.0 & 7.0 \\
\hline Interdig. & $39 L$ & HKP & 4 & $\mathrm{ft}$ & $\mathrm{HG}$ & 11.0 & 13.0 & 7.0 \\
\hline Interdig. & $36 \mathrm{R}$ & HRP & 4 & $\mathrm{ft}$ & $\mathrm{HG}$ & 9.0 & 13.5 & 6.0 \\
\hline Interdig. & $37 \mathrm{~L}$ & Met & $3 b$ & trk & $\mathrm{HG}$ & 10.5 & 12.0 & 7.0 \\
\hline
\end{tabular}

Cases are listed in order of decreasing overlap in the putamen between tracers transported from the cortex and GPe Abbreviations are as in Table 1.

terograde tracer deposits tended to label a greater extent of the striatum than the small retrograde tracer deposits.

The cortical injections in the four cases with the most extensive input-output overlap were in regions representing the foot. Three cases had injections in the foot region of area 4 , and one had an injection in the foot region of area $3 \mathrm{~b}$. The stereotaxic coordinates of the pallidal sites for the four cases are given in Tables 1 and 2. The two GPe injection sites were in roughly similar regions, as were the two GPi injection sites. Moreover, the relation of the GPe and GPi injection site coordinates to each other (the GPi sites being about $1.5 \mathrm{~mm}$ posterior and 1.0 $\mathrm{mm}$ ventral to the GPe sites) is compatible with the sites in GPe and GPi being along the same radially oriented beams of fibers leaving the putamen. This stereotaxic relation is similar to that previously found between injection sites that produced overlap of GPe-projecting and GPi-projecting striatal zones when the two pallidal segments were labeled in a single hemisphere (Flaherty and Graybiel, 1993b).

The input-output alignment in these cases indicates that the GPe and GPi sites we injected received convergent inputs from multiple sites in the putamen that themselves received divergent input from small cortical loci representing the foot. We injected fewer cortical loci representing other body parts, but there was some evidence that reconvergence can occur for other body part representations as well. Figure 4 (case $40 \mathrm{~L}$ ) shows an example in which an anterograde tracer injection was placed in the mouth region of area 4 . In the caudal putamen (but not the rostral putamen) nearly all the output zones labeled by a small injection in GP overlapped the inputs labeled by the cortical injection. Although the lineup of the anterograde and retrograde labeling was not as precise as it was in the four foot cases of Figures 2 and 3 , it was as good as that seen in another of the foot cases (case 39R, not illustrated). The retrograde tracer deposit that labeled the mouth inputs of case $40 \mathrm{~L}$ was somewhat more ventral and caudal in the pallidum than injection sites that retrogradely labeled foot inputs.

\section{Neighboring regions of the pallidum receive distinct corticostriatal inputs}

Of the 31 anterograde-retrograde injection pairs that labeled the same general region of the sensorimotor putamen, 23 labeled striatal input and output zones that predominantly interdigitated with each other. These "interdigitation" pairs did not form a completely discrete category, but were on a continuum between the overlap and miss pairs. For most interdigitation tracer pairs there were some levels where there was at least some overlap, as well as a few rostrocaudal levels where the labeled projections were in different regions of the putamen ("misses"). Because we were unable to record somatosensory responses in the pallidum in our acute preparations, we could not direct the pallidal injection sites to a given body part representation. Therefore, we considered the possibility that this range of patterns was due to inaccurate placement of pallidal injections. Accordingly, for injection site pairs in which the cortical injection site filled only a single body part representation (as it did in 13 of the 23 interdigitation pairs), we could not rule out the possibility that the striatopallidal output zones, though interdigitating with the sensorimotor input zones labeled with that particular injection, might have overlapped with unlabeled sensorimotor cortical inputs from other body part representations.

To control for this possibility, we made a series of injection site pairs in which the cortical injection sites were very large, filling nearly all of either MI or SI cortex. These injections labeled widespread regions of the putamen, and there were therefore fewer "miss" cases following large cortical injections than there were following small ones. Nonetheless, there were seven such pairs (listed in Tables 1 and 2) in which there was practically no overlap of labeled striatopallidal outputs with labeled ipsilateral MI- or SI-input zones. This was seen with both GPi-projecting zones (three pairs) and GPe-projecting zones (four pairs). These cases demonstrated that just as there are small sites in GPe and GPi that receive convergent inputs from striatal 

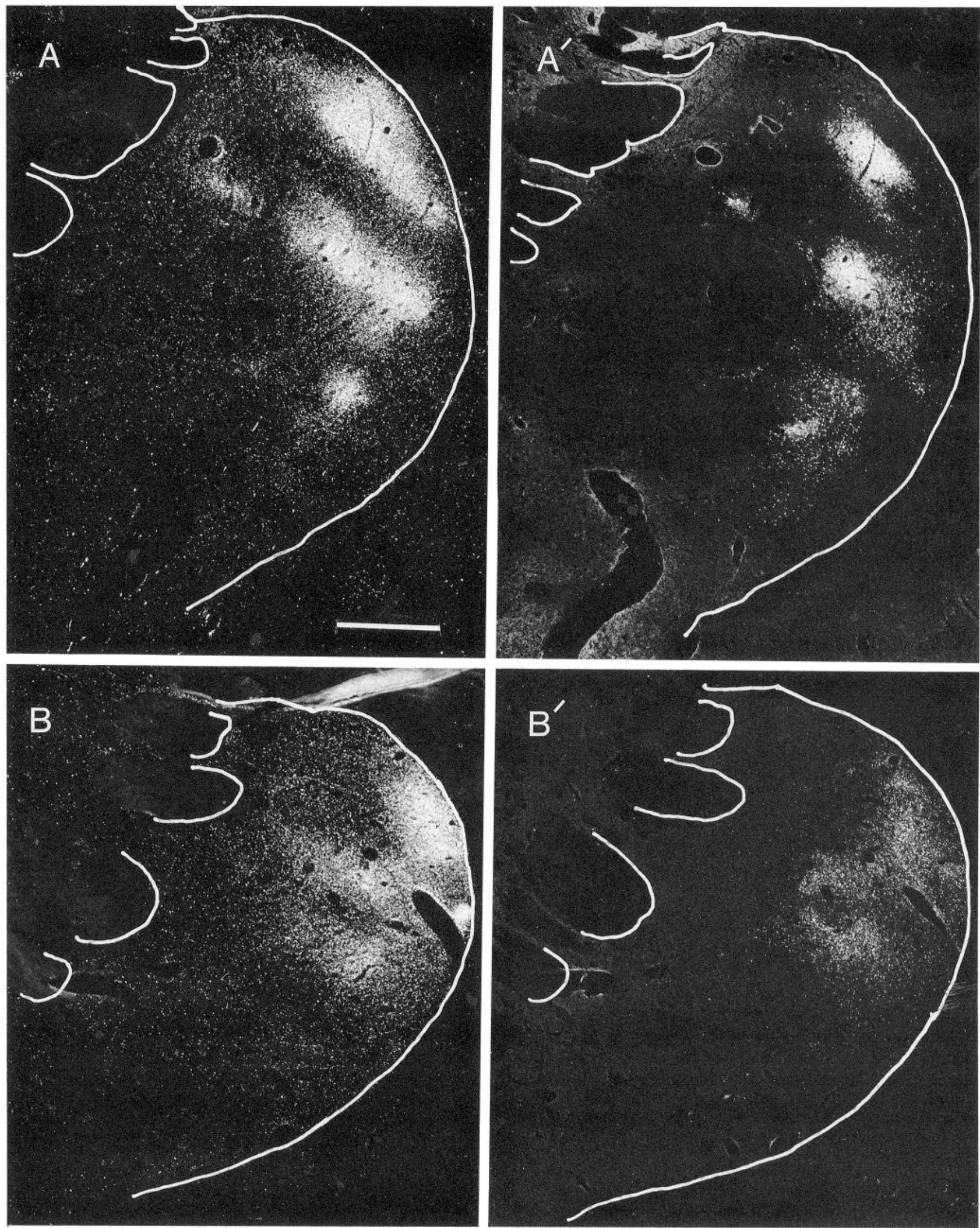

Figure 2. Sets of input matrisomes can be sets of output matrisomes. A, A dark-field photomicrograph of a coronal section (level A 13.0) through the putamen of hemisphere $31 \mathrm{R}$, with input matrisomes anterogradely labeled by an injection of WGA-HRP in the foot region of motor cortex. $A^{\prime}$, A section serial to that in $A$ with output matrisomes retrogradely labeled by an injection of CTB in GPi. $A$ and $A^{\prime}$ are also drawn as overlays in the middle of Figure $3 A^{\prime} . B$, A coronal section (level A 13.5) through the putamen of hemisphere $29 \mathrm{R}$, with input matrisomes anterogradely labeled by an injection of WGA-HRP in the foot region of somatosensory cortex. $B^{\prime}$, A serial section with output matrisomes retrogradely labeled by an injection of CTB in GPe. Borders of the putamen are outlined in white. Tracer injection sites are shown in Figure 3. Scale bar, 1 mm. 


\section{A. Injection sites (31R)}

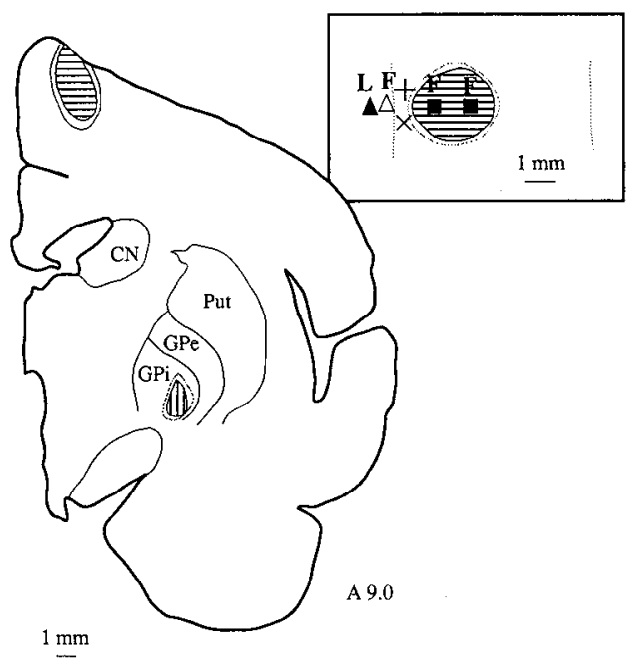

Figure 3. Sets of input and output matrisomes can match over an extended anteroposterior distance. $A$ and $B$, Injection sites. Cortical sites are shown both in coronal sections and normal to the cortex, enlarged and superposed on the electrophysiological maps. Stimulation site conventions are as in Figure 1. Recording sites are marked by the following symbols: $\nabla$, area $3 \mathrm{a} ; \boldsymbol{\Lambda}$, area $3 \mathrm{~b} ; \triangle$, area $1 ; \times$, no recorded somatosensory response. $F$, foot; $L$, leg. $A$, CTB injection site in GPi and WGA-HRP injection in the foot region of MI (hemisphere $31 \mathrm{R}) . B$, CTB injection site in GPe and WGA-HRP injection site in the foot region of SI (hemisphere 29R). $A^{\prime}$ and $B^{\prime}$, Overlay drawings of pairs of serial sections at intervals through the putamen. $A^{\prime}$, Foot sensorimotor cortex inputs line up with GPi outputs (hemisphere $31 \mathrm{R}$ ). The middle pair of sections from which the overlay drawings were made are shown in Figure $2 A . B^{\prime}$, Foot sensorimotor cortex inputs line up with GPe outputs (hemisphere 29R).

\section{A'. Putamen (31R): projections overlap}

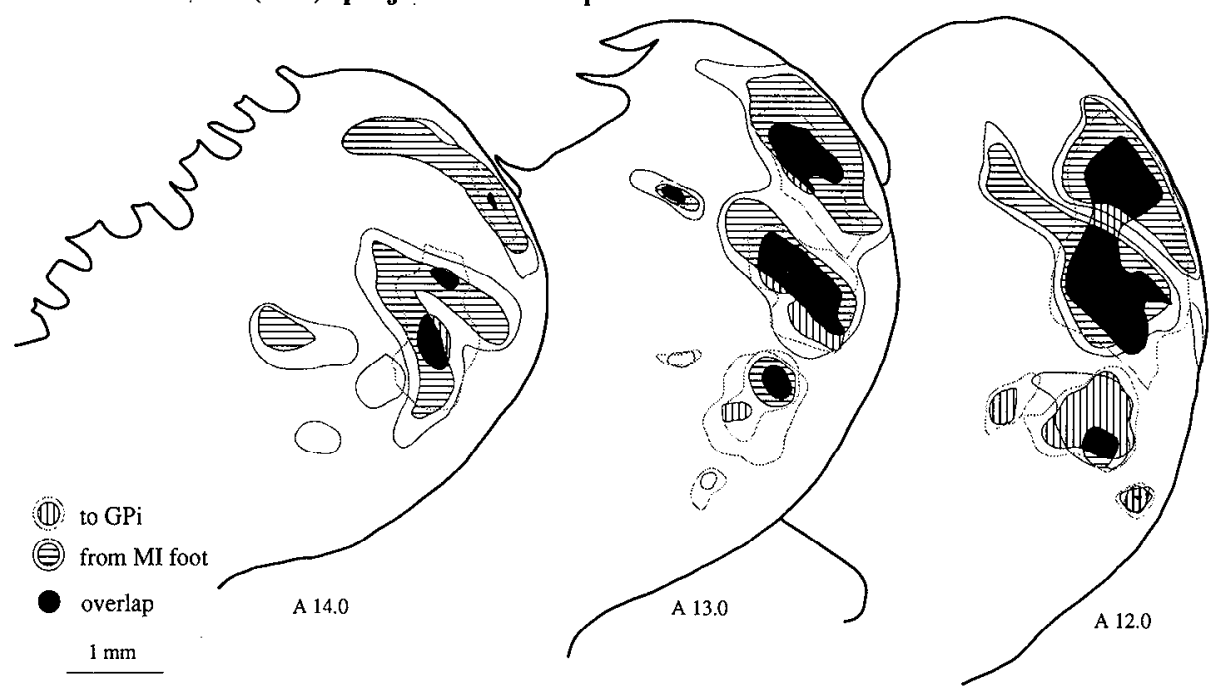

MI/SI-recipient input zones, there are also nearby GPe and GPi sites that do not receive strong input from MI/SI-recipient zones.

Because the contralateral MI cortex innervates a set of striatal inpul zones largely different from but near those receiving ipsilateral MI/SI inputs (Flaherty and Graybiel, 1993a), we considered the possibility that the pallidal outputs might overlap contralateral MI inputs even when they interdigitated with ipsilateral MI inputs. We tested for this in nine injection pairs, by injecting ipsilateral and contralateral MI with different anterograde tracers. There were hemispheres in which labeled output zones did not overlap zones receiving either ipsilateral or contralateral MI inputs (Fig. 5). Thus, even in the apparently motor sector of GP (central and slightly ventral within each segment), there are some sites that do not receive major innervation from either ipsilateral MI/SI cortex or contralateral MI cortex. In a few cases, output zones labeled from ipsilateral MI injections were avoided by inputs labeled from contralateral MI (not shown). There were not sufficient data to indicate whether GPe and GPi output zones differed in this respect.
The pallidal regions that did not receive inputs from sensorimotor input zones were in regions close to the pallidal regions that did (Fig. 6), and the average stereotaxic coordinates of the pallidal injection sites in the overlap and the interdigitation pairs did not differ significantly. Though such cross-animal comparisons have obvious limitations, they suggest that the interdigitation was not simply due to the pallidal injection sites lying far away from the parts of the GPe or GPi that do receive sensorimotor corticostriatal signals. Instead, the evidence suggests that within a single segment of GP, two regions that are near each other can receive input from two different sets of striatal zones receiving different cortical input.

\section{Discussion}

These experiments demonstrate that cortical inputs carrying information about single body parts can diverge to innervate striatal zones whose outputs then reconverge onto discrete sites in both segments of the pallidum. The corticostriatal divergence, therefore, does not invariably divide cortical projections into 


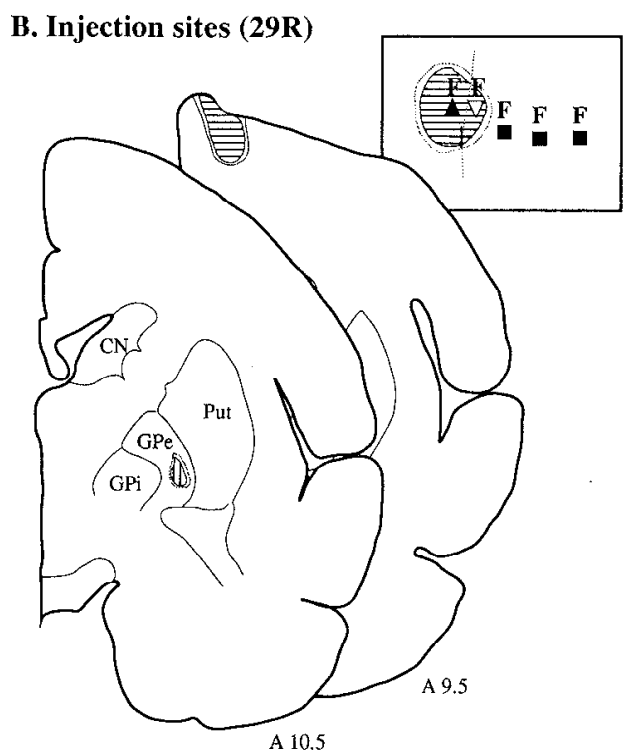

\section{B'. Putamen (29R): projections overlap}

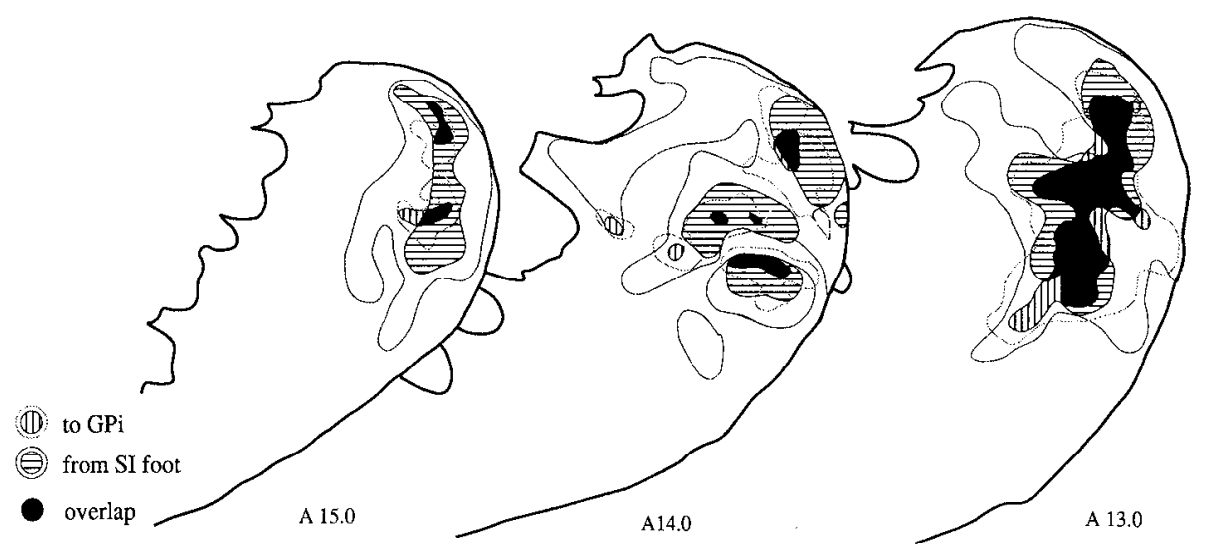

different pathways (e.g., to two different ultimate target nuclei). Rather, one reason for having a striatal processing step in basal ganglia circuitry may be to disperse a given cortical input to multiple sites in the striatum so that novel associations can bc set up between different groups of inputs before the inputs reconverge at the level of the pallidum. Our findings further suggest that pallidal sites receiving $\mathrm{MI} / \mathrm{SI}$ inputs via the striatum lie near pallidal sites lacking MI/SI inputs. The pallidum itself may thus selectively process different sets of corticostriatal inputs for distribution to different outflow targets.

\section{Input matrisomes as output matrisomes}

The patch-for-patch alignment of physiologically identified corticostriatal inputs and striatopallidal outputs was the most striking finding of this study. We observed this reconvergence pattern for both GPe-labeled and GPi-labeled matrisomes, and for cases in which we injected MI as well as for cases in which we injected SI. The lineup of the input and output patches, therefore, was not limited to one category of the connections we studied. Rath- er, there seem to be sets of matrisomes in the sensorimotor putamen that share at least three properties: (1) they receive inputs from the same regions of the cortex, (2) they project to a particular region of GPe, and (3) they project to a particular matched region of GPi. This divergence-reconvergence pattern reinforces the hypothesis that retrogradely and anterogradely labeled matrisomes are indeed functional units rather than random heterogeneities.

We have no evidence that such input-output correspondence is a universal rule. There were many cases in which the labeled inputs and outputs interdigitated with or missed each other. We favor the view that the range of overlap, interdigitation, and miss patterns that occurred with different tracer pairs resulted from uncontrolled variation in the placement of the pallidal injections. Because the retrograde tracers could not be placed in electrophysiologically identified pallidal sites, they may have been to varying degrees in or out of the region corresponding to the physiologically determined cortical injection site in a given tracer pair. If two SI injection sites, for instance, are "off”" 
A. Injection sites (40L)

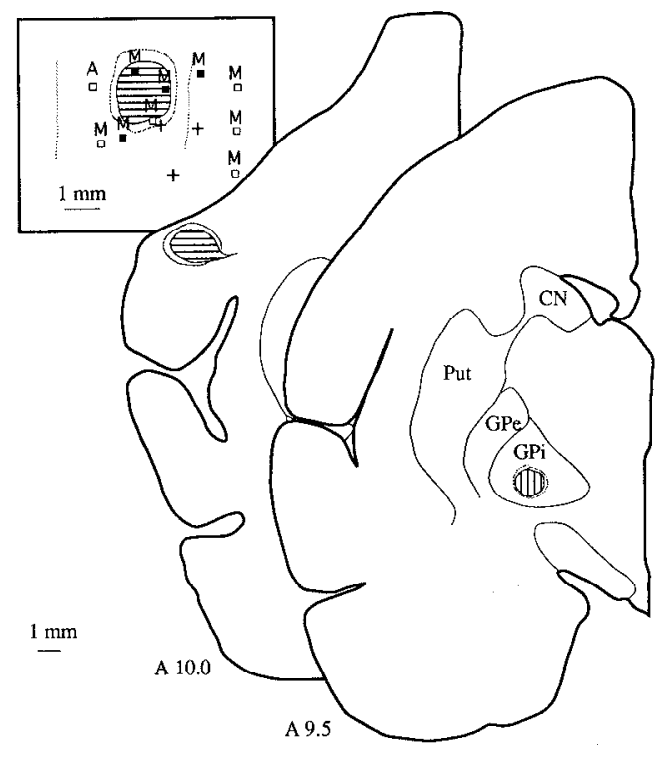

B. Putamen (40L): caudal projections overlap

Figure 4. Rough overlap between mouth $\mathrm{MI}$ input matrisomes labeled by an ${ }^{35} \mathrm{~S}$-methionine injection and GPi output matrisomes labeled by a CTB injection (hemisphere 40L). $A$, Anterograde and retrograde tracer injection sites. The cortical injection site is shown both in coronal section and normal to the cortex, enlarged and superposed on the electrophysiological stimulation and recording map. Stimulation and recording map conventions are as in Figures 1 and 3. $B$, Overlay drawings of pairs of serial sections at intervals through the putamen, in which there are increasing amounts of projection field overlap in more caudal sections.

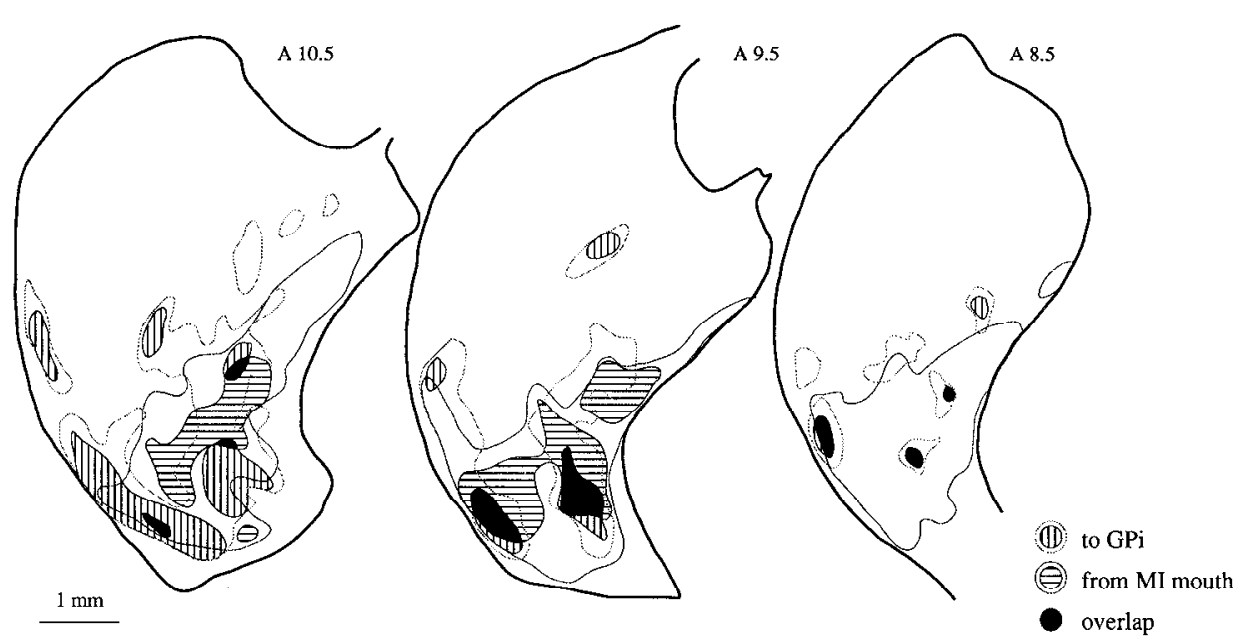

topographically, the patch-for-patch overlap in their striatal projections disappears (Flaherty and Graybiel, 1991). An alternate possibility, of course, is that the relationship between the input and output matrisomes is not ordered but random, or varies from animal to animal, and that the cases of extensive overlap were statistical accidents rather than examples of a functional principle.

The best evidence against this second view is the systematicity of the anterograde-retrograde overlap found in cases such as those illustrated in Figures 2-4. Even if the match between any individual pair of input and output matrisomes could be ascribed to chance, it is highly unlikely that a random relationship would yield the precision of overlap seen, in which nearly the entire set of labeled input matrisomes overlapped the set of output matrisomes throughout most of the mediolateral and rostrocaudal extent of the projection field. Such precision was as good as that found in double-anterograde experiments between sets of input matrisomes innervated by homologous body part regions of MI and SI (Flaherty and Graybiel, 1993a).
What information is aligned by the matching input and output matrisomes?

Input matrisomes receive projections from different cortical representations of homologous body parts in SI (areas 3a, 3b, and 1) and MI (Flaherty and Graybiel, 1991, 1993a). This arrangement suggests that multiple types of sensory information about a given body part are sent to each member of a dispersed set of input matrisomes. For output matrisomes, we have no such functional clues. As discussed above, we had no way to ensure that the regions of the pallidum that we injected were confined to particular body part representations, and we suspect that many of the injection sites were not. However, a reasonable working hypothesis is that the overlap cases in our experiments were those in which homologous body part representations were injected in the cortex and in the pallidum. That would imply that at least a rough somatotopic organization is maintained across corticostriatopallidal connections, even though it is temporarily fractured at the level of the striatum. This view is in 
A. Injection sites (35L, 35R)

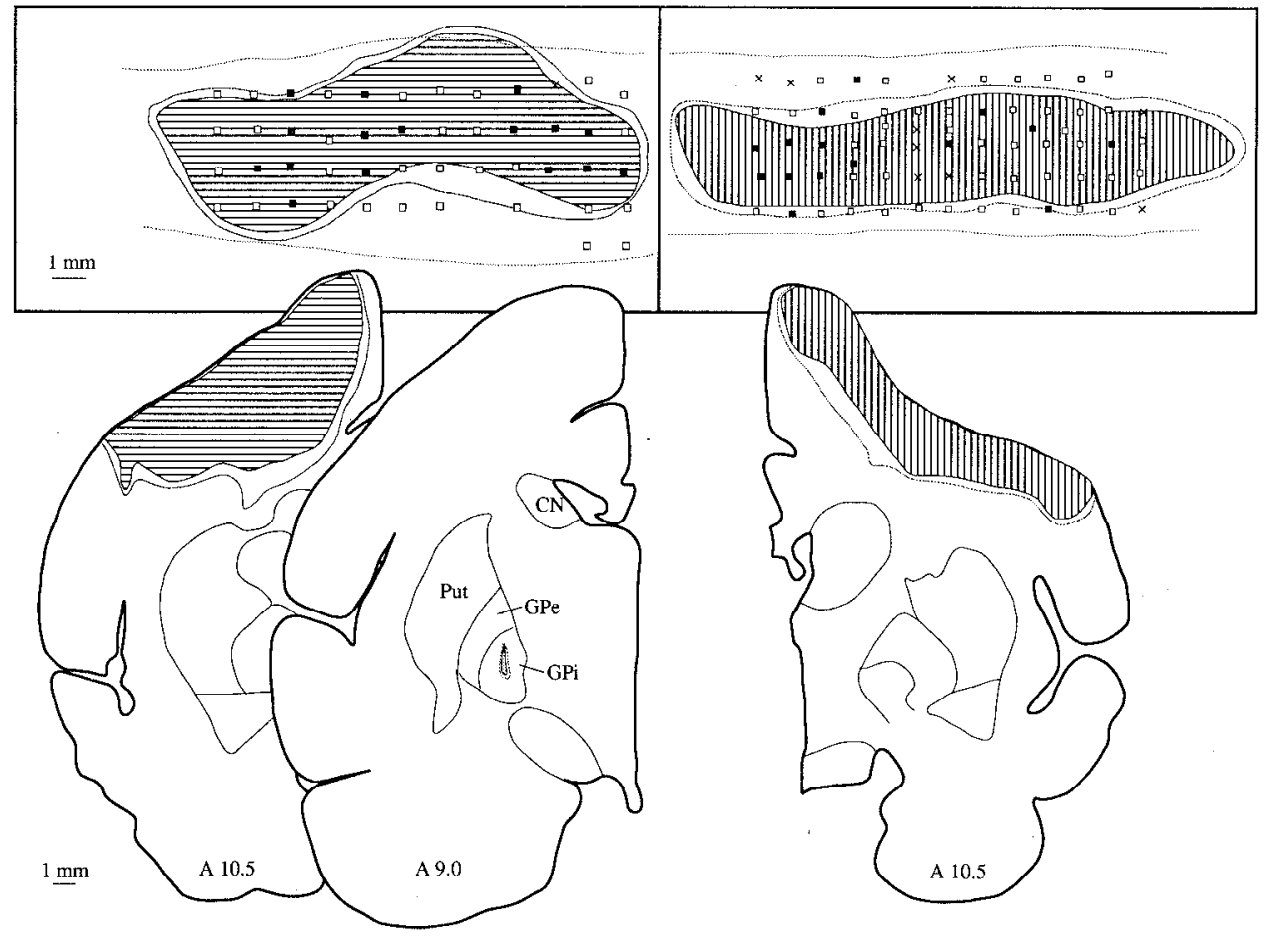

\section{B. Putamen: projections interdigitate}

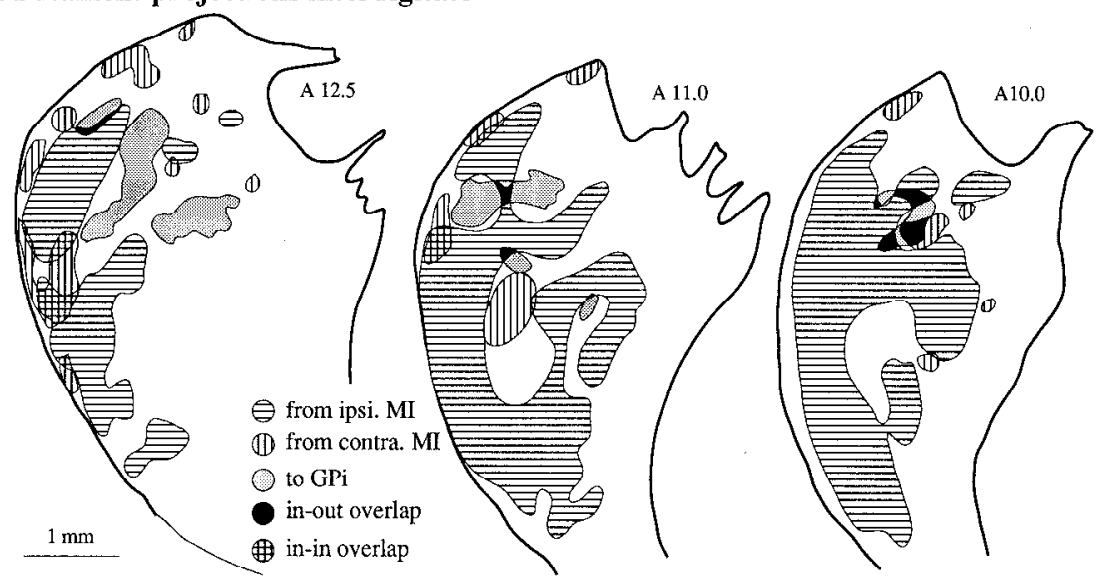

Figure 5. Some GP output matrisomes do not receive motor cortex inputs (an "interdigitation" case). $A$, Cortical and pallidal injection sites (hemispheres 35L, 35R): a WGA-HRP injection site filling most of the left MI, a ${ }^{35} \mathrm{~S}$-methionine injection site filling most of the right MI, and an $\mathrm{HG}$ injection site in the left GPi. Cortical injection sites are shown both in coronal section and normal to the cortex, enlarged and superposed on the electrophysiological stimulation map. Stimulation map conventions are as in Figure 1. $B$, Overlay drawings of three triplets of coronal sections through the left putamen, in which matrisomes receiving inputs from either ipsilateral or contralateral MI interdigitate with output matrisomes projecting to GPi. accord with electrophysiological evidence from recordings made in GPe and GPi (DeLong et al., 1985), and could be tested by making physiological maps of the pallidum and cortex in single animals. Anterograde transneuronal tracer injections in cortex should also be useful (Zemanick et al., 1991).

Other patterns of input-output alignment may coexist with the overlap we saw. First, we confirmed that the heavily labeled input matrisomes in the striatum were usually surrounded by weakly labeled halos of labeling, so some functional innervation may well occur outside the matrisomes with consequent effects on the pallidum. Second, the patterns seen here for sensorimotor matrisomes in the putamen may not hold for other parts of the putamen and caudate nucleus, even though both patchy input and output distributions occur in the matrix of these other regions as well (Ragsdale and Graybiel, 1981; Giménez-Amaya and Graybiel, 1990; Sadikot et al., 1990; Selemon and GoldmanRakic, 1990). Third, even within the sensorimotor putamen, the input-output overlap rule might hold only for particular body part representations or for particular sets of matrisomes. For other sets of matrisomes, convergence of nonhomologous body part representations or of other representational units might occur.

\section{Implications for the output architecture of the striatum}

In previous double-retrograde tracer experiments, we found that GPe-projecting and GPi-projecting neurons are intermixed within many individual output matrisomes (Flaherty and Graybiel, 1993b). However, these observations left open the possibility that the GPe-projecting and GPi-projecting output matrisomes only partly overlap each other, or do so inconsistently or even randomly. The anterograde-retrograde overlaps found in the present study argue against a random relationship of GPe and GPi output matrisomes, because the sensorimotor input matrisomes could line up both with GPe-projecting matrisomes 


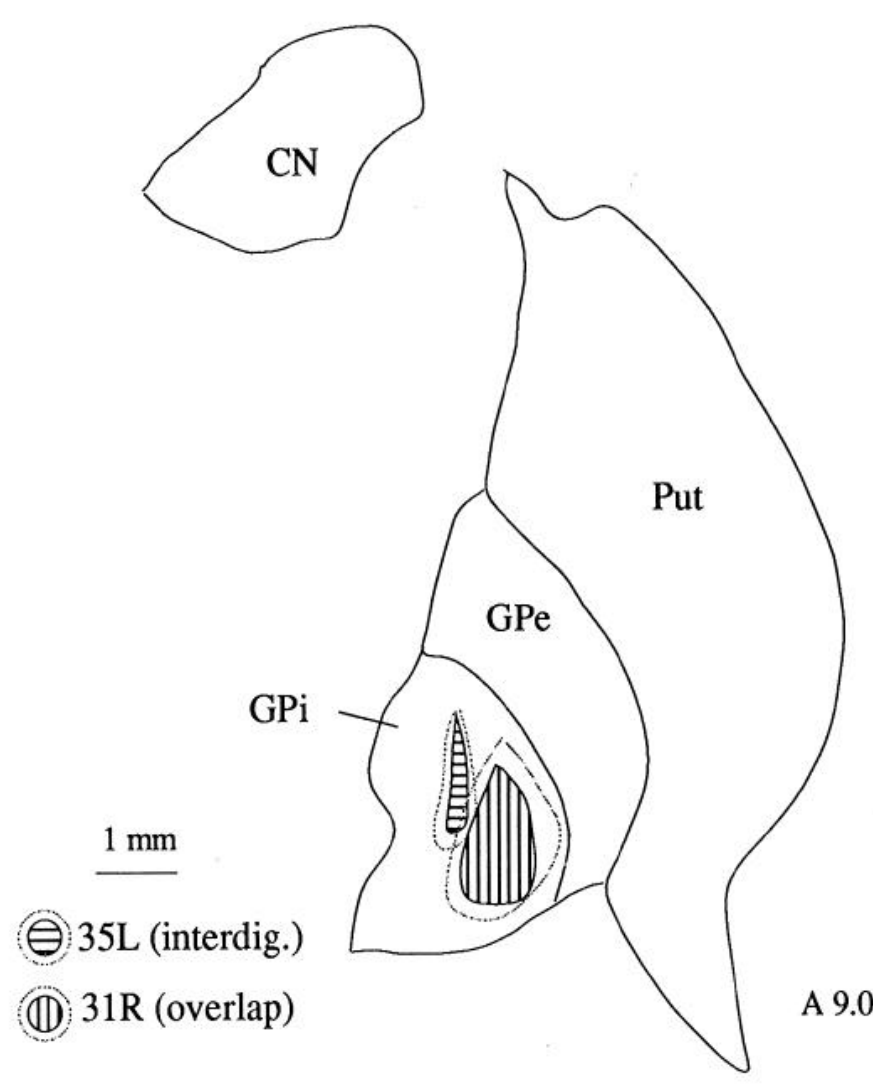

Figure 6. GP sites that receive inputs from sensorimotor matrisomes can be near sites that do not. Horizontal hatching mark the HG injection site in hemisphere $35 \mathrm{~L}$, which labeled matrisomes receiving little motor cortex input; vertical hatching mark the CTB injection site in hemisphere $3 \mathrm{IR}$, which received heavy motor cortex input from the foot region. The injection sites have been projected onto standard atlas sections; that of $35 \mathrm{~L}$ has been drawn reversed for ease of comparison.

and with GPi-projecting matrisomes. It is difficult to imagine how nearly every input matrisome in a set could overlap nearly every output matrisome projecting to a small region of GPe, and also overlap nearly every output matrisome projecting to a small region of GPi, while still having many of the output matrisomes projecting to one of the pallidal segments and not the other. These results therefore suggest that a given set of matrisomes sending outputs to a small locus in GPe can also send outputs to a small, homologous locus in GPi. A summary diagram of this model is shown in Figure $7 A$.

Such a system could ensure that certain sets of GPe-projecting and GPi-projecting neurons are controlled in a coordinated fashion. This coordination is compatible with the assumption made by current models of basal ganglia processing, that pathways through GPe and GPi in the basal ganglia work in tandem to control movement, either by being in opposition (see Crossman, 1987; Albin et al., 1989), or by having complementary actions (Mink and Thach, 1991b).

\section{Implications for the input architecture of the pallidum}

The pallidal sites that received converging inputs from sets of $\mathrm{MI} / \mathrm{SI}$ matrisomes and those that receive little or no input from $\mathrm{MI} / \mathrm{SI}$ matrisomes were not in widely separated parts of the pallidum. Both types occurred in the central and somewhat ventral parts of the pallidum, where sensorimotor responses have been recorded (DeLong et al., 1985; Mink and Thach, 1991a). This location suggests that GPe and GPi may not only have a general dorsoventral topography, but also, within any given region, may contain subregions targeted by different striatopallidal inputs (Fig. $7 B$ ). Such heterogeneous input architecture may be related to local inhomogeneities in response properties of pallidal neurons (Hamada et al., 1990), and is also in accord with transneuronal tracing experiments suggesting that different parts of GPi project via discrete output channels to different premotor cortical areas (Hoover and Strick, 1993).

Inputs sent by way of the striatum from one or more areas of the premotor, supplementary motor, or parietal cortex, or from the thalamus, are likely sources of inputs to regions of the pallidum adjacent to those receiving SI/MI-derived sensorimotor inputs. The contralateral cortex is another possibility (Flaherty and Graybiel, 1993a). The present experiments indicate that some sets of output matrisomes interdigitate with both ipsilateral and contralateral MI input matrisomes, but we found that others seem to be preferentially innervated by ipsilateral rather than contralateral inputs.

\section{Striatal modules as functional units}

Why is the corticostriatal projection divergent if, in at least some instances, the dispersed information is brought together again by the striatopallidal projection? One possibility is that the di-

\section{A. Reconvergence to both segments}

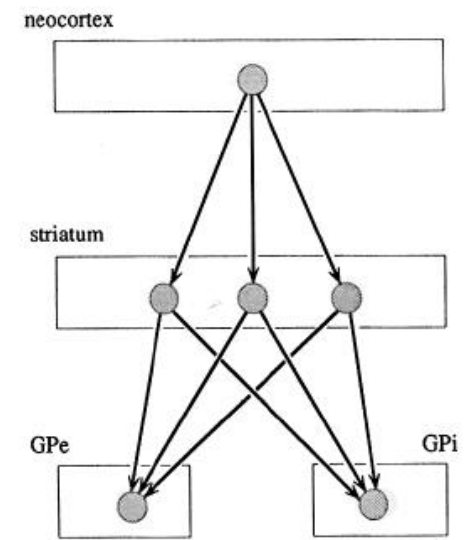

\section{B. Nonconvergence to each segment}

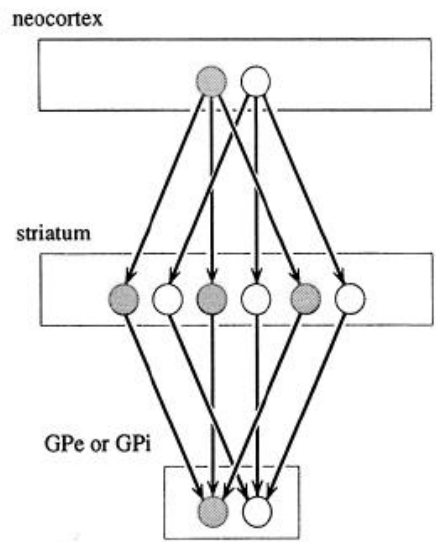

Figure 7. Two aspects of a model suggested by the experimental findings. $A$, Outputs from single body part representations in MI or SI cortex diverge to innervate a set of striatal matrisomes, which in turn send outputs that reconverge on small, possibly homologous sites in GPe and GPi. $B$, Nearby sites in the cortex innervate separate sets of matrisomes, which then reconverge on nearby sites within each GP segment (only one of which is shown). The different sets of matrisomes can interact with each other and with striosomes (not shown) along their borders. 
vergence increases the degree to which a given cortical input could interact on a local level with other striatal inputs and with interneuronal systems - that the divergence is a device for associative processing (Malach and Graybiel, 1986; Brown, 1992). Breaking up the input from a single cortical region into a distributed set of matrisomes would increase the surface area at the borders of the input system available for such interactions with other matrisomes and with striosomes (Fig. 7B). Such a fracturing of input topography is predicted for a mapping system in which both local and nonlocal interactions are important (Nelson and Bower, 1990).

The idca that clumping of striatal input-output systems promotes local interactions between clumps has so far only been tested anatomically, and then only for striosomes and the surrounding matrix. Interestingly, the boundaries of striosomes appear to have distinctive characteristics (Beach and McGeer, 1984; Chesselet and Graybiel, 1986; Steindler et al., 1988; Faull et al., 1989). The dendritic arbors of certain cell types appear to avoid crossing striosumal boundaries (Bolam et al., 1988; Kawaguchi et al., 1990; Walker et al., 1993). No information is available about these sorts of interactions at the boundaries of matrisomes, and there is as yet no evidence that matrisomes are strictly bounded the way striosomes seem to be. Matrisomes have relatively fuzzy borders compared to striosomes, and, even in the most compelling cases of input-output overlap, the borders of the labeled zones were never in perfect alignment. Matrisomes may thus represent waxing and waning distributions of innervation that overlap along their perimeters, rather than all-or-none compartmental units.

These interactions could be a substrate for associative learning in the basal ganglia. The corticostriatal divergence would, according to this hypothesis, allow new sensorimotor associations to form through repeated engagement of particular sets of matrisomes with other matrisomes and striosomes at their borders. The convergence of different SI and MI inputs on sets of matrisomes could produce coherent activity in clusters of striatal output neurons when their shared sensory and motor input systems are appropriately coactivated. The striatopallidal reconvergence might reassemble the projections into somatotopic maps following processing in the striatum. Corticostriatal signals could thus engage appropriately, but with modifiable content or associative strengths, the output pathways of the basal ganglia, including those leading to frontal lobe sites implicated in working memory and motor learning (Fuster, 1989). Both long-term potentiation and long-term depression have been demonstrated in the striatum (Calabresi et al., 1992a,b), and both acute and prolonged pharmacological treatments have been found to change the patterns of gene expression in striatopallidal circuits (e.g., Graybiel et al. 1990; Gerten et al., 1991; Berretta et al., 1992; Hurd and Herkenham, 1992). Evidence for plasticity of neuronal responsivity has been demonstrated both in the striatum (Aosaki et al., 1992, 1993) and in the midbrain dopaminecontaining cell groups that project to it (Ljungberg et al., 1992). It would be of considerable interest to know if these phenomena are related to the input-output templates described here.

\section{References}

Albin RL, Young AB, Penney JB (1989) The functional anatomy of basal ganglia disorders. Trends Neurosci 12:366-375.

Alexander GE, Crutcher MD (1990) Functional architecture of basal ganglia circuits: neural substrates of parallel processing. Trends Neurosci 13:266-272.

Aosaki T, Ishida A, Watanabe K, Imai H, Graybiel AM, Kimura M
(1992) Effects of dopaminergic agents on the tonically active neurons of the striatum in hemi-parkinsonian monkeys. Soc Neurosci Abstr 18:693.

Aosaki T, Tsubokawa H, Watanabe K, Graybiel AM, Kimura M (1993) Tonically active neurons in the primate striatum acquire responses to sensory stimuli during behavioral conditioning. Soc Neurosci Abstr, in press.

Basbaum AI, Menetrey D (1987) WGA-apoHRP gold: a new retrograde tracer for light- and electron-microscopic single- and doublelabel studies. J Comp Neurol 261:306-318.

Baxter LR Jr, Schwartz JM, Bergman KS, Szuba MP, Guze BH, Mazziotta JC, Alazraki A, Selin CE, Ferng H-K, Phelps ME (1992) Caudate glucose metabolic rate changes with both drug and behavioral therapy of obsessive-compulsive disorder. Arch Gen Psychiatry 49: 681-689.

Beach TG, McGeer EG (1984) The distribution of substance $P$ in the primate basal ganglia: an immunohistochemical study of the baboon and human brain. Neuroscience 13:29-52.

Berretta S, Robertson HA, Graybiel AM (1992) Dopamine and glutamate agonists stimulate neuron-specific transcriptional activation of $\mathrm{c}$-fos in the striatum. J Neurophysiol 68:767-777.

Bolam JP, Izzo PN, Graybiel AM (1988) Cellular substrate of the histochemically-defined striosome/matrix system of the caudate nucleus: a combined Golgi and immunocytochemical study in cat and ferret. Neuroscience 24:853-875.

Brown LL (1992) Somatotopic organization in rat striatum: evidence for a combinational map. Proc Natl Acad Sci USA 89:7403-7407.

Calabresi P, Maj R, Pisani A, Mercuri NB, Bernardi G (1992a) Longterm synaptic depression in the striatum: physiological and pharmacological characterization. J Neurosci 12:4224-4233.

Calabresi P, Pisani A, Mercuri NB, Bernardi G (1992b) Long-term potentiation in the striatum is unmasked by removing the voltagedependent magnesium block of NMDA receptor channels. Eur J Neurosci 4:929-935.

Chesselet M-F, Graybiel AM (1986) Striatal neurons expressing somatostatin-like immunoreactivity: evidence for a peptidergic interneuronal system in the cat. Neuroscience 17:547-571.

Crossman AR (1987) Primate models of dyskinesia: the experimental approach to the study of basal ganglia-related involuntary movement disorders. Neuroscience 21:1-40.

DeLong MR, Crutcher MD, Georgopoulos AP (1985) Primate globus pallidus and subthalamic nucleus: functional organisation. J Neurophysiol 53:530-543.

Faull RLM, Dragunow M, Villiger JW (1989) The distribution of neurotensin receptors and acetylcholinesterase in the human caudate nucleus: evidence for the existence of a third neurochemical compartment. Brain Res 488:381-386.

Flaherty AW, Graybiel AM (1990) Proprioception and the striatum: primate somatosensory cortical area 3 a projects more broadly to the striatum than do areas $3 b$ or 1 . Soc Neurosci Abstr 16:1231.

Flaherty AW, Graybiel AM (1991) Corticostriatal transformations in the primate somatosensory system. Projections from physiologically mapped body-part representations. J Neurophysiol 66:1249-1263.

Flaherty AW, Graybiel AM (1993a) Two input systems for body representation in the primate striatal matrix. J Neurosci 13:1120-1137.

Flaherty AW, Graybiel AM (1993b) Output architecture of the putamen. J Neurosci 13:3222-3273.

Fuster JM (1989) The prefrontal cortex. New York: Raven.

Gerfen CR, McGinty JF, Young WS III (1991) Dopamine differentially regulates dynorphin, substance $\mathrm{P}$, and enkephalin expression in striatal neurons: in situ hybridization histochemical analysis. J Neurosci 11:1016-1031.

Gergen JA, MacLean PD (1962) A stereotaxic atlas of the squirrel monkey's brain (Saimiri sciureus). Bethesda: National Institutes of Health.

Giménez-Amaya J-M, Graybiel AM (1990) Compartmental origins of the striatopallidal projection in the primate. Neuroscience $34: 111-$ 126.

Giménez-Amaya J-M, Graybiel AM (1991) Modular organization of projection neurons in the matrix compartment of the primate striatum. J Neurosci 11:779-791.

Graybiel AM, Moratalla R, Robertson HA (1990) Amphetamine and cocaine induce drug-specific activation of the c-fos gene in striosomematrix and limbic subdivisions of the striatum. Proc Natl Acad Sci USA 87:6912-6916. 
Graybiel AM, Flaherty AW, Giménez-Amaya J-M (1991) Striosomes and matrisomes. In: The basal ganglia, III (Bernardi $G$, Carpenter MB, di Chiara G, Morelli M, Stanzione P, eds), pp 3-12. New York: Plenum.

Hamada I, DeLong MR, Mano N-I (1990) Activity of identified wristrelated pallidal neurons during step and ramp wrist movements in the monkey. J Neurophysiol 64:1892-1906.

Hoover JE, Strick PL (1993) Multiple output channels in the basal ganglia. Science 259:819-821.

Hurd YL, Herkenham M (1992) Influence of a single injection of cocaine, amphetamine or GBR 12909 on mRNA expression of striatal neuropeptides. Brain Res 16:97 104.

Kawaguchi Y, Wilson CJ, Emson PC (1990) Projection subtypes of rat neostriatal matrix cells revealed by intracellular injection of biocytin. J Neurosci 10:3421-3438.

Ljungberg T, Apicella P, Schultz W (1992) Responses of monkey dopamine neurons during learning of behavioral reactions. J Neurophysiol 67:145-163.

Luppi P-H, Sakai K, Salvert D, Fort P, Jouvet M (1987) Peptidergic hypothalamic afferents to the cat nucleus raphe pallidus as revealed by a double immunostaining technique using unconjugated cholera toxin as a retrograde tracer. Brain Res 402:339-345.

Malach R, Graybiel AM (1986) Mosaic architecture of the somatic sensory-recipient sector of the cat's striatum. J Neurosci 6:3436-3458.

Mink JW, Thach WT (1991a) Basal ganglia motor control. I. Nonexclusive relation of pallidal discharge to five movement modes. J Neurophysiol 65:273-300.

Mink JW, Thach WT (1991b) Basal ganglia motor control. III. Pallidal ablation: normal reaction time, muscle cocontraction, and slow movement. J Neurophysiol 65:330-351.

Nelson ME, Bower JM (1990) Brain maps and parallel computers. Trends Neurosci 13:403-408.

Parent A, Hazrati L-N (1993) Anatomical aspects of information processing in primate basal ganglia. Trends Neurosci 16:111-116.
Ragsdale CW, Graybiel AM (1981) The fronto-striatal projection in the cat and monkey and its relationship to inhomogeneities established by acetylcholinesterase histochemistry. Brain Res 208:259266.

Rubin RT, Villanueva-Meyer J, Ananth J, Trajmar PG, Mena I (1992) Regional xenon 133 cerebral blood flow and cerebral technetium $99 \mathrm{~m}$ $\mathrm{HMPAO}$ uptake in unmedicated patients with obsessive-compulsive disorder and matched normal control subjects. Arch Gen Psychiatry 49:695-702.

Sadikot AF, Parent A, Francois C (1990) The centre median and parafascicular thalamic nuclei project respectively to the sensorimotor and associativc-limbic striatal territories in the squirrel monkey. Brain Res 510:161-165.

Selemon LD, Goldman-Rakic PS (1990) Topographical intermingling of striatonigral and striatopallidal neurons in the rhesus monkey. Comp Neurol 297:359-376.

Sessle BJ, Wiesendanger M (1982) Structural and functional definition of the motor cortex in the monkey (Macaca fascicularis). J Physiol (Lond) 323:245-265.

Steindler DA, O'Brien TF, Cooper NGF (1988) Glycoconjugate boundaries during early postnatal development of the neostriatal mosaic. J Comp Neurol 267:357-369.

Swedo SE, Pietrini P, Leonard HL, Schapiro MB, Rettew DC, Goldberger EL, Rapoport SI, Rapoport JL, Grady CL (1992) Cerebral glucose metabolism in childhood-onset obsessive-compulsive disorder. Arch Gen Psychiatry 49:690-694.

Walker RH, Arbuthnott GW, Graybiel AM (1993) Dendritic domains of medium spiny neurons in the primate striatum: relationships to striosomal borders. J Comp Neurol 336:1-15.

Zemanick MC, Strick PL, Dix RD (1991) Direction of transneuronal transport of herpes simplex virus 1 in the primate motor system is strain-dependent. Proc Natl Acad Sci USA 88:8048-8051. 